\title{
Language, medical tourism and the enterprising self
}

Sebastian Muth and Neelakshi Suryanarayan

\begin{abstract}
This paper aims to demonstrate the implications of health mobility on language practices in the medical tourism industry in India and on the ways, language workers become entrepreneurs. Drawing from ethnographic fieldwork that traces the trajectories of three former students of Russian, we highlight their future aspirations as language learners and entrepreneurs and show, how they attempt to capitalize on language skills and respond to changing conditions and patient movements within the structures, constraints and uncertainties of the linguistic market. Here, it is our aim to illustrate what it takes to become an enterprising and successful language worker and at the same time highlight their current positioning as emblematic yet subordinate figures within a fast-growing service industry in an emerging economy. We further demonstrate, how language skills not only become commodities to serve existing or future markets, but instead are recast as tools that can be strategically employed to secure recognition and access to prestigious and lucrative professional networks. In doing so, this paper illustrates how linguistic value is produced in a service industry that to date only received little attention in sociolinguistic research.
\end{abstract}

Keywords: language and healthcare, language and work, India, medical tourism, language commodification

\section{Introduction}

In a time when low standards and ineffectiveness of medical care continue to have devastating consequences on patients in India and beyond (Kruk et al. 2018), the growing prominence of medical tourism and the availability of medical services across borders is indicative of larger structures of inequalities that frequently deny access to fundamental services such as healthcare or education. At the same time, the rise in the number of patients travelling abroad to undergo medical procedures and the revenues this generates for local healthcare industries has been impressive. Although to date no comprehensive data on the scope of this form of health mobility exists and numbers vary (Connell 2015; Hazarika 2010), estimates value the annual turnover of global medical tourism at around 61 billion USD in 2016, a number that is projected to rise to 160 billion USD by 2023 (Allied Market Research 2017).

With healthcare emerging as a commodity on a global marketplace, so does language. As patients become consumers, interpreters, multilingual service workers and healthcare brokers emerge as central figures in the creation of a distinct and marketable image of hospitality and professional care. Along the same line, multilingual repertoires come into view as indispensable tools that ensure market expansion and the creation of professional networks in current and future healthcare markets (Connell 2013; Muth 2017, 2018). This also characterizes the wider context of this paper that aims to demonstrate the implications of this form of health mobility on language practices in the medical tourism industry in India and on the ways, 
language workers become entrepreneurs who set out to capitalize on their language skills in the care for medical tourists. For this, we will draw from ethnographic observations of three former students of Russian who graduated from a public university in the Indian capital Delhi and who are or aspire to become healthcare brokers to capitalize on a recent surge in patients coming to India to seek medical attention. Finding themselves within a framework that requires constant adjustments and adaptations, we highlight their future aspirations as language learners and entrepreneurs and show, how they attempt to capitalize on language skills and respond to changing conditions and patient movements within the structures, constraints and uncertainties of the linguistic market. Here, it is our aim to illustrate what it takes to become an enterprising and successful language worker and at the same time highlight their current positioning as emblematic yet subordinate figures within a fast-growing service industry in an emerging economy. We further demonstrate, how language skills not only become commodities to serve existing or future markets, but instead are recast as tools that can be strategically employed to secure recognition and access to prestigious and lucrative professional networks. In doing so, this paper illustrates how linguistic value is produced in a service industry that to date only received little attention in sociolinguistic research.

The connection of linguistic production and economic productivity (Boutet 2008; Duchêne 2011) is reflected in other sectors of the service economy where the needs of a diverse range of consumers need to be linguistically accommodated. Based on the notion of language as a form of symbolic capital that may or may not find exchange value (Bourdieu 1977, 1991), language and communication skills can be exchanged for various forms of capital gain on specific markets within specific contexts (Cameron 2012; Cavanaugh 2016; Heller and Duchêne 2016; Tan and Rubdy 2008) and as such become objects of both corporate and individual aspiration (Park 2011, 2016; Urciuoli 2008). Medical tourism as a service industry reliant on multilingual speakers highlights just this. With language learning becoming a technology of the self (Foucault 1997), it exemplifies the relationship between language practice and entrepreneurism in a context where language matters as a central working tool (Cameron 2000; Duchêne 2009, 2011; Heller 2003, 2010). However, at the same time it also illustrates how language becomes a medium of potentiality that allows speakers to achieve what they aspire to as self-responsible neoliberal subjects (Park 2016). The characteristics and consequences of the relationship between language and the neoliberal economy have been subject to research in a wide array of settings, among them tourism, education, marketing, and communication (Heller and Duchêne 2016; Muth and Del Percio 2018; Tan and Rubdy 2008). Frequently recast as commodities with fluctuating values attached to it, languages and multilingual repertoires signal a distinctive property of the speaker and furthermore serve to manage and maintain complex work tasks, organizational structures as well as ensure access to both global and local professional networks (Bishop et al. 2005; Cameron 2000; Dlaske 2016; Duchêne 2011; Piller and Takahashi 2013). However, the commodity value of any language is fluctuating and dependent on the structures and constraints of the linguistic market (Park 2011), entailing a considerable amount of uncertainty and speculation (Duchêne 2009, 2011; Muth 2018).

In the following, we begin by giving an overview of medical tourism and the emergence of a global healthcare market as a consequence of neoliberal governance and the privatization and corporatization of 
medical services. This is followed by a discussion of the medical tourism industry in India as our research context that in in the past two decades witnessed a significant growth in both revenue and patient numbers. We will then show how language practices are connected to language work in healthcare, highlight the role of language in the care for medical tourists coming to India and further illustrate the motivations and pathways of becoming a language worker within this industry. Based on fieldnotes, participant observations and interviews that ranged from September 2016 until March 2019, we will then describe the professional trajectories, activities and future aspirations of three former students of Russian who embarked on a career within the medical tourism industry at four 'multi-speciality' hospitals within the Greater Delhi area. Based on ethnographic accounts of their aspirations, their strategic investments into language and their efforts to become multilingual medical professionals, we will argue that the valuation of language skills and communicative conduct is firmly embedded within neoliberal economic structures, not easy to predict and dependent on wider social structures of inequality in the country. We will conclude that a large part of language work is characterized by tensions between future aspirations of entrepreneurial success and own insecurities about language skills and uncertainty within volatile market conditions. In line with neoliberal ideology (Harvey 2005; Gershon 2011), current and future healthcare markets must be read, anticipated and engaged with to profit from a rapidly growing yet largely unregulated service industry. Further, in order to stand out it is up to the individual speaker to strategically invest in one's own multilingualism, professional knowledge, and communicative conduct (Del Percio 2018; Urciuoli 2008; Park 2016), adhering to an imperative of constant self-improvement.

\section{The globalization of healthcare}

Indeed, few sites are better suited to illustrate global inequalities than medical tourism and the global mobility of patients across national borders. Framed within a neoliberal understanding to privatize all aspects of social life and promoted by international financial organizations and national governments as a form of economic development for emerging economies and third world countries alike (Connell 2013; Ormond 2013; Smith 2012), in the past decade medical tourism emerged as a multi-billion Dollar industry with global dimensions and local consequences. This also resulted in a shift to market-driven healthcare systems in several emerging economies, frequently implemented as part of Structural Adjustment Programs by the World Bank and the International Monetary Fund to reduce public expenditures in healthcare and establish private healthcare sectors that would also seek revenues by attracting patients from abroad (Ormond 2013; Smith 2012). Following the logics of this form of neoliberal governance, a strong private medical sector promised to lead to greater investments in local healthcare industries, a growing number of healthcare specialists, growing medical expertise and - more broadly - would result in an increase in national income, thus providing greater numbers of the population access to quality healthcare (Fort et al. 2005; Smith 2012: 4). Especially in developing nations and emerging economies a state-of-the-art private medical sector promised to be beneficial to local healthcare systems as it would open employment opportunities for medical professionals, hospitality workers and interpreters alike, contribute to the development of a skilled 
workforce and a professionalization and modernization of both the healthcare sector and local tourism industries (Connell 2016, Gola 2016).

The designation of this form of health mobility as 'tourism' is not without controversy as it suggests a form of voluntary leisure travel to improve one's health by seeking medical care wherever you choose to. However, at this point scholars (Connell 2016; Smith 2012) suggest that while the notion of medical tourism implies “[...] leisure and frivolity" (Smith 2012: 3) and as such lacks a neutral perspective, it nevertheless has the potential to highlight the very characteristics and consequences of a neoliberal industry. Relating to language work it makes sense to decouple the medical tourism industry from the individual experience of medical travel, as regardless of the location, destination branding by medical providers frequently resorts to images from the hospitality industry to promote their services (Muth 2018; Smith 2012) - patients are readily accommodated in the language of their choice, health interpreters become hospitality managers or concierges, hospital rooms become luxury suites and guided touristic activities are frequently advertised alongside medical procedures. It is then within the prevailing paradigm of the neoliberal economy that brings the oftentimes uncomfortable practices of the industry into a much sharper focus (Smith 2012; Shetty 2010).

While there exists a persistent image that medical tourism is closely connected to individual choice, entitlement and luxury (Allied Market Research 2017; Smith and Puczkó 2014), this only holds true from a historic perspective when cross-border journeys were only possible to a privileged few to a small number of destination countries such as France or Switzerland (Muth 2018). In fact, a large part of medical tourism flows are not constituted of affluent patients from developed countries seeking better-value treatment in destinations where healthcare costs are significantly lower or were waiting times to undergo a particular procedure are shorter; instead, a large share of patients make a conscious choice to travel as they have no access to adequate and high-quality healthcare in their home countries. These patient flows are then not necessarily from center to periphery and from industrialized nations to the developing world, but from within the global peripheries themselves: Byelorussians travel to Lithuania for surgery, Iraqi patients undergo treatment at Lebanese hospitals, Kenyan patients enquire about hospital stays in South Africa while those Congolese who can afford it travel as far as India to seek medical attention (Connell 2016; Dewachi et al. 2018; Muth 2017; Österle et al. 2009; Stan 2015). Concurrently to this, medical tourism has a decidedly local dimension that finds its expression in local and regional patient flows and cross-border travel where patients travel to undergo non-invasive treatment, for instance in dental care where Austrians travel to Hungary or Greeks visit physicians across the border in Macedonia (Connell 2016).

\section{3 'First-world care at third world prices' - Medical tourism to India}

At present, India has one of the most liberalized and privatized healthcare systems of the world that to a large extent mirrors the country's social and economic inequalities. Until the 1980s and first efforts to establish private medical-service providers, healthcare in India was dominated by the country's public and not-for-profit sectors. Because of rising public debt and the subsequent adoption of structural adjustment 
policies imposed by the International Monetary Fund, India embarked on a 'New Economic Policy' that saw the rise of the private healthcare sector and increasing foreign investment especially into corporate hospital groups such as Apollo, Fortis Healthcare or Mittal Hospital that are owned by industrial conglomerates (Smith 2013: 5-6). This healthcare sector is also at the forefront of India's entry into the global healthcare market and as such also part of a government strategy to attract revenue from abroad. In relation to scope, patient numbers and overall revenues, no comprehensive data exists, and it is estimated that in 2015 amounted in a turnover between USD2-3 Billion that is projected to grow by at least 25 percent until 2020 (Business Standard 2017; The Economic Times 2015). Between July 2015 and July 2016 India issued around 220.000 medical visa with most recipients coming from Bangladesh, Afghanistan, Iraq, Nigeria, Oman, Iran, Kenya, Pakistan, and the Democratic Republic of Congo (IMTJ 2017). Nevertheless, some patients arrive on a tourist visa and within the industry and by government bodies it is estimated that within the same timeframe the number amounts to 460.000 (IMTJ 2017), among them patients from Kazakhstan, Tajikistan, Turkmenistan, Uzbekistan, Russia as well as the United States. Exemplarily, the Apollo Hospital Group that is the largest provider of private healthcare in the country claims that between 2016 and 2017 roughly 170.000 'international' patients received treatment at their hospitals (Business Standard 2017). Medical tourist coming to the country for treatment are mostly attracted by a preferential visa policy for medical tourists, lower treatment costs if compared to most other destination countries, as well as the availability of English-speaking physicians and care workers (Gola 2016; Sharma 2013). With regard to our research context, to raise the attractiveness of healthcare services in post-Soviet markets and in order to accommodate a growing number of medical tourists, private hospitals in the Delhi-area began to recruit university graduates of Russian since 2009 (Suryanarayan 2017), a practice that also extends to other languages such as Arabic, Farsi, French and Pashto.

In that respect, despite the availability of English-speaking medical personnel in larger facilities, target markets for healthcare providers suggest that English-proficiency alone is hardly enough to succeed in this industry. While with regard to affluent medical tourists past research suggests that English may indeed be desired as a matter of prestige in favour of one's own first language (Muth 2018), a multilingual workforce is frequently regarded both as a necessity to avoid misunderstandings and additional treatment costs (Kaspar and Reddy 2017; Suryanarayan 2017) as well as a central marketing argument and integral part of marketing and promotional discourses (Connell 2016; Muth 2017). Nonetheless, as we will also demonstrate this does not limit the overall appeal of English as a language that promises entrepreneurial success. While the origins of most patients do not suggest that any promise of English in promotional discourses matters to them, from the perspective of language workers English may become a strategic instrument in order to acquire medical knowledge and to gain access to professional networks and stakeholders within the local medical tourism industry. 


\section{Methodology and participants}

For this research, we focus on ethnographic observations of the work routines, multilingual practices and narrations of three former students of Russian we call Narendra, Ahmad and Goral. During the various stages of our research all three worked at or in cooperation with hospitals either in Delhi or in the largest of several newly formed satellite cities around the Indian capital, Gurgaon in the state of Haryana. During their careers in the medical tourism industry they worked under numerous professional designations such as medical interpreter, healthcare broker, patient buddy or international patient manager and ultimately aspired to become healthcare brokers for international patients. We were able to establish contact with them through our networks at the university department where they had graduated. All three speakers of Russian this paper introduces became acquainted with medical interpreting and hospitality work for Russian-speaking patients during their studies and were already in casual employment with hospitals when we approached them. At that time, their responsibilities as multilingual service workers were manifold: They were not only specialized in a certain language or patient group but are also employed because of their specific communicative conduct, personal traits such as being punctual, discreet and service-minded as well as a their comprehensive cultural background knowledge of the potential target markets they specialize in through their linguistic repertoire and communication skills (Connell 2013; Muth 2017, 2018). At the beginning of our research, all three were positioned within an intricate hierarchy of both casual and permanent employment and depend on current and projected patient numbers that determine their workload and, ultimately, their income. Ahmad, a native speaker of Urdu is the most senior of our informants and throughout the time of research had worked as a healthcare broker throughout this research. Narendra is a native speaker of Hindi and after studying Russian he did casual medical work and further worked in an outsourcing hub to write invoices for companies from Russia. He entered the healthcare industry after responding to a job offer for a marketing expert for Russian-speaking patients at a Delhi hospital that he continued to hold throughout this research. Goral regards himself as a multilingual speaker of Kashmiri and Hindi. Similar to Ahmad and Narendra he performed ad-hoc medical interpreting work during his studies and in the course of this research transitioned from Russian-speaking hospital interpreter and service worker to independent broker for medical services.

Our observations took place in, around, or in transit between four hospitals in Delhi and Gurgaon. When our research started, all the of them had established designated 'International Lounges', 'International Centers' or 'International Patient Units'. These organizational structures are in place to coordinate and administer foreign patient visits and to assign non-English speaking foreign patients to suitable hospitality workers at the hospital. Ethnographic fieldwork began in October 2016 and so far, consists of three rounds of fieldwork that each lasted from 14 to 23 days each, one during October and November 2016, one during December 2017 as well as the latest visit during February and March 2019. This longitudinal perspective allows us to trace the working lives and aspirations of the former students over time, follow their trajectories and document their investments and tactics to remain competitive within the local medical tourism industry. Our fieldwork aimed at documenting their everyday working lives with a focus on language practice and 
language-related activities such as interpreting, translating as well as professional and casual interactions with colleagues, physicians and patients. Further, documenting daily work routines through fieldnotes and comparing those over time enabled us to better understand the ways in which beliefs about their professional future as speakers of Russian were shaped by changing market conditions and their own hierarchical positioning within the industry. This allowed us to identify activities tied in to future entrepreneurial success, such as language learning, networking among physicians, the acquisition of key medical terminology, a certain professional conduct like punctuality or appearance. Fieldnotes were compiled in English and interviews and conversations with the three informants were mainly conducted in Russian, English and occasionally Hindi. As especially at the beginning of the research in 2016 our informants were more proficient in Russian than English, it proved to be of advantage that both researchers are proficient in this language as it enabled us to better follow interactions among informants and patients.

\section{Planning careers: languages and aspirations}

Work in the medical tourism industry to a large extent is characteristic of interactive service work where language can be exchanged for different forms of capital gain and where value is ascribed to certain multilingual resources (Cameron 2012; Dlaske 2016; Heller and Duchêne 2016; Park 2011, 2016; Tan and Rubdy 2008). This frequently entails a considerably high degree of uncertainty and speculation for speakers as much as it requires certain investments especially in a globalized service industry where the commodity value of language is negotiated in volatile market conditions (Muth 2017; Ormond 2013). This volatility workers have to address also applies to niche languages such as Russian in India that only has a limited appeal and, since the end of the Soviet Union, is mainly used in tourism contexts (Suryanarayan 2017). In fact, neither Narendra, Ahmad nor Goral made conscious decisions to learn Russian in order to later capitalize on their language skills but instead saw it as one of their few options to obtain a degree in higher education and the trajectories of all three initially did not suggest a career in medical tourism. However, as much as their work is reliant on marketable language skills, work in this industry also entails having a particular conduct in interactions with patients and physicians, much alike to efforts to police or stylize speakers into prescribed ways of talk or communicative behaviour (Cameron 2000; Duchêne 2016; Katz 2001; Lorente 2017).

Their aspirations to capitalize on Russian grew once opportunities opened to perform interpreting work at private hospitals. At that time around 2010, Delhi hospitals witnessed a surge in patient numbers from Central Asian countries that had been part of the Soviet Union and where large shares of the population speak Russian as a second or first language. While all three were accustomed to performing paid interpreting work or acting as guides for Russian-speaking tour groups during their studies, the rise in demand for Russian speakers at hospitals opened up an entirely new perspective of regular work in a fast-growing service industry. When recruitment of students of Russian as casual interpreters and hospitality workers became commonplace around 2010, Narendra, Ahmad and Goral became involved in the care for Russianspeaking patients. They did so either through fellow students or teachers (Suryanarayan 2017), or - in case 
they already graduated - through networks of speakers and learners of Russian who are organized in Facebook and WhatsApp groups such as Narendra. Once they entered this form of language and service work, it soon emerged that being able to speak Russian was only one aspect of the activity to guide medical tourists through their treatment in Delhi. During our first round of fieldwork in 2016, Ahmad recalls his first steps as an interpreter and ad-hoc patient manager as a time of excitement and uncertainty. "Before the hospital asked me to interpret for a patient from Russia, I did not know this existed. I was not very good in Russian and did not know any medical terminology - I even texted my teacher at the department. 'What does this [word] mean in Russian?' But soon you learn, you understand what is important in this job." (Ahmad, October 2016). Indeed, he soon became aware that this form of service work required more than conversational Russian-skills but instead also called for a basic understanding of medical procedures as well as for adequate health literacy in Russian, Hindi, but also English as the professional language of physicians. Yet unlike in language- and communication-based work where speakers are frequently subjected to scripted language (Lorente 2017; Katz 2001), where prescribed ways of talk are commonplace (Cameron 2000), where language ideologies are reproduced as professional hierarchies (Rahman 2009), or where workers are made to fit into particular institutional narratives (Wee 2015), Ahmad was left on his own to find ways and resources to improve himself both as a speaker of Russian and as a healthcare professional. In that respect, he soon regarded himself as an entrepreneur by chance who is fully responsible for his own success and failures yet lacking the support of institutional networks or resources (Ahmad December 2017). As much as this enterprising around language and professionalism remained speculative for Ahmad, it nevertheless opened up a path of upward mobility that could not have been expected with a university degree in Russian. Referring back to his aspiration to become a healthcare broker when he was still a student and freelance interpreter, he recalls "I witnessed that more and more patients were coming and they [the hospitals] had problems finding interpreters so there was my chance. You can do this if you speak a little Russian, no problem, but you will never move on to become a broker or anyone. If you want to achieve something you have to work hard." (Ahmad, December 2017). Here, Ahmad already internalized what the neoliberal self entails, as it is up to him alone to succeed in this profession. He also soon realized that there was a demand for reliable and skilled Russian speakers and a niche he could tap into. Framed within a notion of opportunity to capitalize on patient flows and enter this presumably lucrative service industry, he acknowledges that language proficiency is the key requirement that makes mainly casual employment possible. However, in order to advance and in order to build a career, different personal traits and professional skills become equally important even if this means to endure hardships, showing how notions of both self-regulation and self-realization (Del Percio 2018; Urciuoli 2008) are instrumental in order to become and remain competitive. Because of his resilience, dedication and readiness to acquire key medical terminology in Russian, as soon as he graduated in 2013, he became a regularly-employed patient manager at a reputable private hospital in Gurgaon. Ahmad's career progressed further and to some of his fellow students he evolved into a role-model of entrepreneurial success. 
One of them is Narendra and when we met him for a day of participant observation in 2017, our conversation quickly turned to recent news about Ahmad, whom we were also following around the same time. In fact, both knew each other peripherally, but since Ahmad had just recently made a successful transition from hospital-employed interpreter and hospitality worker to international healthcare broker and entrepreneur, his achievement became the projection of Narendra's own aspirations. "I want to be like him, independent, everybody I know wants that" he told us (Narendra, December 2017). Currently however, this remains an aspiration as he finds himself in the middle of a hierarchical order of language workers and interpreters in medical tourism that has been described as emblematic for this form of service work (Kaspar and Reddy 2017; Suryanarayan 2017). Similar to Ahmad, along his trajectory he had passed through periods of casual employment as healthcare interpreter and even tourist guide to become a 'marketing specialist for Russian' at a Delhi hospital owned by an Indian industrial conglomerate. At the time of this conversation, Narendra was tasked with the discussion of treatment plans, the organization of airport transfers for patients and their relatives, the written translation of medical records from English into Russian, as well as the organization of touristic activities and shopping trips in case these are requested. He further oversees and manages a changing number of associate patient service managers who were employed on monthly contracts as medical interpreters and hospitality workers for Russian speaking patients.

Being employed by an international office of a private hospital is largely seen as a way to acquire a wide range of transferable skills that are regarded is indispensable to progress in this industry that prepare you for what might lie ahead. Narendra illustrates this during a conversation about his future aspirations and desirable personal skills and traits during a round of participant observation (Narendra, December 2017): "You have to have a certain attitude. You constantly learn - language, medical terminology, how to look, how to talk, how to build a network [of doctors and patients]." Strikingly resembling Ahmad's above narration on how he learned to walk in the industry, Narendra's subscription to continuous personal selfdevelopment illustrates what is central to entrepreneurial success within a potentially unstable market, among them mastering the right language, improving one's personal- and professional conduct with physician and patients, and becoming health literate. In that respect, it takes a certain 'attitude' and dedication to self-evaluation and change as key elements of entrepreneurial success. However, within these beliefs and in line with other contexts where both communicative conduct and language skills matter (Lorente 2017; Park 2011; Park and Wee 2012), language remains key to their material success, albeit within the constraints and characteristics of the linguistic market.

\section{Staying ahead: investments in language}

Indeed, language matters as a resource that can be strategically acquired, deployed and developed for profit (Cameron 2000; Duchêne and Heller 2012; Park 2016). It pervades language work and as such, is also instrumental to entrepreneurial success in the Delhi medical tourism industry. This holds true for our informants as well, as their Russian-skills and status as (former) students of Russian made their entry into language work possible. Nonetheless, future entrepreneurial success is not inextricably linked to mastering 
Russian but instead dependent on the speaker's ability to adapt to circumstances where any language may be of potential value. It is within this context that language learning becomes a technology of the self (Foucault 1997) that helps to realize this potential and that can be strategically employed whenever new opportunities emerge. Exemplarily, Goral illustrates this when outlining his future plans for market expansion. He is the third of our informants who in 2017 started to work as a healthcare broker with Uzbekistan as his key market. "Russian is important for my work, but I have observed my patients, they are bilingual but sometimes more confident in Uzbek. I went there [Uzbekistan] for promotion work and I realized that I needed some Uzbek skills, not only to understand patients but to show appreciation for them" (Goral, December 2017). Seeing what symbolic capital might lie in knowing Uzbek, Goral teamed up with an Uzbek entrepreneur who started to promote Goral's brokering services in Uzbekistan. He supplies Goral with magazines, newspapers and doctor's letters in Uzbek and while he is not enrolled in any formal language training, Goral goes at great lengths to acquire a basic conversational knowledge and memorize key phrases of medical terminology (Goral, December 2017), underscoring how within a neoliberal logic, any language can become a "medium of potentiality that allows a speaker to achieve anything she wishes to" (Park 2016, 454). Yet at the same time, investments in language can take different forms not primarily meant to increase patient numbers in existing markets or by expanding to new ones that require different linguistic repertoires. Although Goral's attempt to learn and capitalize on Uzbek highlights a strategic choice in order to secure market shares, investments in language are not necessarily market driven but instead serve more implicit goals.

Narendra illustrates just this by underscoring the role of English for him and others in this profession. Reporting on a recent interaction with a physician who oversaw the treatment of a Kazakh patient he was in charge of at that time, Narendra highlights how English reinforces social hierarchies at the hospital and at the same time became desirable to learn. "The doctors all know Hindi, but you have to know English to understand what they are saying to the patient. Especially medical terminology but also in general. I struggle and they [the doctors] see you as uneducated and stupid because you cannot answer them. I need to learn it properly" (Narendra, December 2017). While this excerpt shows the perseverance of ideologies of English as a language of prestige in a postcolonial setting (Rahman 2009) as much as it highlights Narendra's own subordinate positioning just because he is a speaker who 'struggles with English', it also lays out two key incentives why he should and will invest into learning it. For once, it has practical implications, both to understand English-language medical terminology that is used in conversations and doctor's letters, and in order to access information on medical conditions that is most comprehensive and readily available in English. More importantly though, his motivation to acquire English ties in with his beliefs that professional recognition can only be gained through this language. While this has a clearly symbolic dimension that relates to Narendra's place in the hierarchy of hospital workers, it can also become a strategic choice to build networks of competent and trusted physicians in and around Delhi once the step of becoming an independent healthcare broker is complete. Asked about the role English has for him in this profession, this becomes evident: "English is important in order to become a successful broker as doctors think better 
of you if you know English. Patients from Kazakhstan, Uzbekistan, Turkmenistan now request certain doctors who have shown good treatment results and I need good relations with those doctors" (Narendra, December 2017). For Narendra, mastering English promises access to professional networks that he sees as instrumental for securing a future career in medical tourism, illustrating a powerful and persistent image of English as a language of unlimited potential (Park 2011) that, unlike Russian or Uzbek is not limited to particular nation states or groups of speakers. For him, learning English ensures better accessibility to medical knowledge and helps to properly comprehend interactions between physician and patient, yet it is only through those social and professional hierarchies Narendra attempts to overcome, that its imminent value becomes visible. Implicitly this also suggest a form of future market expansion through his belief that reputable physicians deliver good treatment results that eventually would help build his reputation in postSoviet healthcare markets.

Cultivating one's own linguistic value beyond Russian also became salient for Ahmad. When we met him in 2016 during his transition towards becoming an independent healthcare broker, he was just beginning to recognize the importance of additional language skills. At that time, he was still speculating about the potential value and positive effects of him being multilingual, with an understanding that the more languages he knows, the more successful he will be as a healthcare broker: "It gives a clear advantage if you know many languages, speaking another language and understanding another culture opens up new markets. If I would know Pashto or Arabic, I would have a huge potential as a broker. I could profit from the growing Afghan and Iraqi markets" (Ahmad, November 2016). Eventually this did not materialize and Ahmad never attempted to learn either Pashto or Arabic to capitalize on the growing numbers of patients from war-torn regions for whom India is one of the few options to seek medical attention. At that time, however, he did not speculate on the convertibility of English skills on the profit of his enterprise, largely because he did not master the language and was convinced that he does not need it as his patients "never speak English" (Ahmad, November 2016).

Moving a little over two years forward, this had profoundly changed. When talking to him in front of his former university about his current prospects in medical tourism in February 2019, we do so in English, marking a profound and striking change to what always had been conversations in either Hindi or, most of the time, Russian. After reporting on recent interpreting work he performed for - as he calls - 'celebrity patients' from Uzbekistan, he outlines what had is different since we last observed his work in December 2017. “Already a while ago I noticed that I cannot work without speaking English. I don't have Englishspeaking patients, but I realized that if I want to network and expand my business, I need it. I'm now in those negotiations where I need to understand and speak English" (Ahmad, February 2019). The negotiations he is referring to are indicative of his recent entrepreneurial success and relate to a planned partnership with investors from Saudi-Arabia wanting to finance a hospital designated for medical tourists in the Delhi area (Ahmad, February 2018). While his Saudi partners seem to value his expertise in the local medical tourism industry as much as they appreciate his positive reputation and far-ranging contacts in post-Soviet healthcare markets, Ahmad acknowledges that without his investments into learning English, this would 
not have been possible. In fact, using similar techniques as Goral when he started to acquire Uzbek, Ahmad made use of everything that was available to him, primarily English-language media, TV shows and by utilizing free language-learning apps on his phone, but did not rely on language courses or any formal instruction (Ahmad, February 2018). Mirroring both Goral and Narendra's subscription to personal selfimprovement through language learning, for him English became key in accessing potentially lucrative professional networks, both locally and abroad.

The accounts of all three describe language learning as having two distinct yet interrelated goals. On the one hand, it can be regarded as a strategic investment to secure market shares through the expansion of linguistic repertoires with language becoming a commodity that gives additional value to the service offered (Heller 2010; Rubdy and Tan 2008). These investments not only refer to Russian as the language that made entry into medical tourism possible, but instead are based on individual speculations, experiences and market projections that may make additional language skills desirable. On the other hand, language learning becomes an expression of language ideologies (Rahman 2009), with English being regarded as a key to material success and recognition (Park 2011, 2016; Piller and Cho 2013; Piller and Lising 2014) and a tool that provides access to professional networks that otherwise would have been impossible for them to join. While both goals illustrate language as a central working tool and product (Duchêne 2010; Heller 2011), these are nevertheless dependent on the structures and constraints of the linguistic market and its inherent unpredictability (Park 2011). Exemplified by the different positionings of Narendra, Ahmad and Goral as entrepreneurs, this also shows, how different circumstances and contexts shape individual speculations about the value of linguistic repertoires and as such show, how different regimes of linguistic value (Appadurai 1986) operate even for the same language. Exemplarily, while Ahmad's speculations about the usevalue of languages other than Russian or English remained hypothetical and vague, Goral began to invest in Uzbek skills in order to serve his patients better and to appeal to them. Contrary to that, he never attached any particular value to English, a conviction Ahmad held until his business expanded and he potential it may provide. However, their investments into language - and more broadly into communication - did not end there.

\section{Becoming professional: medical knowledge and the skilled self}

As much as multilingualism is indicative of this form of interactive service work where language itself signals future potential (Park 2016; Park and Bae, this issue), medical expertise and a specific communicative conduct are equally required of healthcare brokers and interpreters. Corresponding to the notion that sees languages as sets of distinct skills, the ability to make informed decisions and to communicate those to patients is equally central to successful entrepreneurship in medical tourism. Contrary to that, interpreting skills hardly matter and are rather seen as a question of language proficiency than profound knowledge of techniques to handle intercultural encounters. As Goral recalls during a conversation at the international lounge of a hospital complex in Gurgaon, he frequently struggled when interpreting consultations between physicians and his patients and when communicating possible treatment options to them afterwards: "The most 
difficult part is really the medical terminology and the whole knowledge behind it. When I started, I did not know much about diseases like cancer and I had problems to express certain words in Russian. But it was also hard to make the right decisions, what is best for the patient. This is left to us" (Goral, December 2017). Strikingly, a large part of decision-making is done by healthcare brokers like Goral and while physicians inform about available treatment options, he must weigh in various factors before making an informed choice as to which treatment suits the patient best. In that respect, he is tasked to communicate how each procedure is performed, to know possible risks, to consider what patients can or cannot afford and further must know what medication and aftercare is available to patients in their home countries. To address his own uncertainties about the use of appropriate medical terminology, he developed a strategy to become more confident in interactions with patients and resorts to memorizing the wording and content of medical reports that patients bring along from home or send in advance. For virtually all patients from post-Soviet Central Asia these are written in Russian and thus provide him with the necessary medical terminology and key phrases associated with commonly recurring medical conditions (Goral December 2017).

For Narendra, a profound knowledge of medical terminology is equally central to his profession and while he is only aspiring to be a broker, his employers require him to perform similar tasks, including to obtain informed consent from patients and explaining medical procedures: "They [the doctors] leave it to me to explain, they don't bother. I had a patient who required a kidney transplant and it was left to me to explain the procedure. I knew I had to prepare in advance, so I memorized the Russian-language Wikipedia page for this" (Narendra, November 2017). Indeed, the stakes are high and both learning medical procedures by heart and communicating this knowledge to patients become indispensable skills, regardless of being a broker or aspiring to become one. Apart from the ability to memorize seemingly complex medical contexts, mastering this is both dependent on language skills and background knowledge on where to retrieve information. On the one hand, this remains associated to proficiency in Russian and, as we discussed before, to mastering English once careers progress further; on the other hand, it closely relates to the ability to gather and identify the most suited, reputable and trusted sources of information. It is within this framework that becoming competent in medical encounters emerges as a strategic investment for all three of our informants. Although it initially remained a question of being able to master key terminology in Russian in order to interpret interactions between patients and physicians, having a profound background knowledge of commonly recurring medical conditions emerged as indispensable for future careers.

\section{Conclusion}

Cultivating one's linguistic knowledge emerged as a central element of interpreting-, consulting- and brokering work in the Delhi medical tourism industry. We have discussed, how individuals who ensure that this economy continues to grow at a spectacular pace make sense of their part in a neoliberal industry that is characterized by uncertainty, flexibility and a hierarchical work order but at the same time rewards selfrealization and self-improvement within the structures and constraints of the linguistic market. Similar to what has been demonstrated elsewhere in different contexts of language work within neoliberal economies 
(Cameron 2000; Del Percio 2018; Duchêne 2011; Park 2016; Rahman 2009), aspiring for a career in the medical tourism industry requires continuous investments and self-work, with language as the central work tool and product. As we have demonstrated along the trajectories of three aspiring healthcare entrepreneurs, language skills indeed became commodities and as such, central in attempts to access potentially lucrative foreign healthcare markets. This is best exemplified by Russian, a language where demand in the form of Russian-speaking patients is high, yet the availability of suitable speakers of Russian remains comparatively low, thus opening perspectives for future careers in a fast-growing service industry. However, even in the light of a momentarily stable linguistic market that per se seems to attach value to speakers of Russian, there is much to lose. In that respect, adjustments must be made in order to remain competitive, either when language preferences of patients gradually change or new medical tourism markets suddenly become accessible or, on the contrary, close down.

Certainly, within this part of the neoliberal healthcare economy, proving to master a language that is currently in demand such as Russian likely secures a position, yet to move beyond dependency or casual employment, speakers must make additional investments into language and in particular into English. In doing so they acknowledged their subordinate positioning both as language workers in a service industry and, within Indian society at large, as non-speakers of English. In that respect, learning English is both necessary and opportunistic as it offers to let go of the constraints of only being able to operate on certain markets (Park 2016) - for once, it imposes not the same risks learning a niche language would mean. Further, comprehending English ensures that no information is lost in interactions between patients and physicians and further helps to gather valuable medical knowledge. Moreover, once aspirations grow it also promises professional recognition, access to the best physicians as well as entry into prestigious local and transnational networks of stakeholders in the medical tourism industry. However, English also illustrates how different circumstances and sites of circulation result in different understandings of linguistic value. Narendra and Ahmad illustrate these different regimes of value (Appadurai 1986) based on their own experiences and trajectories in the medical tourism industry. When Narendra's experiences of working among Englishspeaking physicians made him acutely aware of his own subordinate positioning within the professional hierarchy of the hospital and as such posed a serious obstacle in his aspirations to become a broker, Ahmad only had his patients and future markets in mind. During the earlier stages of his career, he rather made investments into Russian as his main working language, but also shared the belief that proficiency in other languages might expand his business. Only when presented with the opportunity to gain access to lucrative transnational networks in the form of Saudi investors did he recognize the relevance of English as a strategic investment.

Thus, what is required are constant adaptations to own strategies, foresight and an ability to read markets, linguistic or otherwise. Reflecting technologies of the self (Foucault 1997), these present themselves in various ways: through strategic language learning, through the memorization and selection of medical terminology or through efforts to build networks of trusted physicians at home and abroad. Set within a framework that calls for continuous improvement within a potentially volatile industry wholly relying on 
the unobstructed flow of both individuals and capital, building a career on one language alone is a risky endeavour. At the same time however, not taking the risk may even suggest missed opportunities that one can hardly afford. It is also within this context, that language becomes a medium of potentiality (Park 2016), describing a context where investments in language are being made to make new markets accessible and secure existing ones.

Acknowledgements: We would like to thank Ahmad, Goral and Narendra for sharing their working lives with us. We also thank Alexandre Duchêne and Aneta Pavlenko for their support and encouragement to pursue this research, Uta Papen for commenting on an earlier version of this paper and two anonymous reviewers for their insightful comments. All mistakes are our own.

Funding: Schweizerischer Nationalfonds zur Förderung der Wissenschaftlichen Forschung, (Funder Id: http://dx.doi.org/10.13039/501100001711, Grant Number: 159852 as part of a larger research project 'A Web of Care').

\section{References}

Allied Market Research 2017. Medical Tourism Market by Treatment Type (Cardiovascular Treatment, Orthopedic Treatment, Neurological Treatment, Cancer Treatment, Fertility Treatment, and Others) Global Opportunity Analysis and Industry Forecast, 2017-2023. Portland: AMR.

Appadurai, A. 1986. Introduction: Commodities and the politics of value. In A. Appadurai (Ed.), The social life of things: Commodities in cultural perspective (3-63). Cambridge: Cambridge University Press.

Bishop, H., Coupland, N., \& Garrett, P. 2005. Globalisation, advertising and language choice: Shifting values for Welsh and Welshness in Y Drych, 1851-2001. Multilingua 24(4): 343-378.

Bourdieu, P. 1977. The economics of linguistic exchange. Social Science Information 16(6): 645-668.

Bourdieu, P. 1991. Language and symbolic power. In J. B. Thompson (Ed.). Cambridge, MA: Harvard University Press.

Boutet, J. 2008. La vie verbale au travail: Des manufactures aux centres d'appels. Paris: Octares.

Cameron, D. 2000. Styling the Worker: Gender and the Commodification of Language in the Globalized Service Economy. Journal of Sociolinguistics 4: 323-347.

Cameron, D. 2012. The commodification of language: English as a global commodity. In T. Nevalainen \& E. C. Traugott (Eds.), The Oxford handbook of the history of English (352-361). Oxford: Oxford University Press.

Cavanaugh, J. R. 2016. Talk as work: Economic sociability in Northern Italian heritage food production. Language and Communication, 48, 41-52.

Connell, John 2013. Contemporary medical tourism: Conceptualisation, culture and commodification. Tourism Management, 34: 1-13.

Connell, John 2015. Transnational Health Care: Global Markets and Local Marginalisation in Medical Tourism. In P. Bronwyn, B. Greenhough, T. Brown, I. Dyck (Eds.), Bodies Across Borders: The Global Circulation of Body Parts, Medical Tourists and Professionals (75-94). Farnham: Ashgate.

Connell, John 2016. Reducing the scale? From global images to border crossings in medical tourism. Global Networks 16:4, 531-550. 
Del Percio, A. 2018. Engineering commodifiable workers: language, migration and the governmentality of the self. Language Policy 17 (2): 239-259.

Dewachi, O, Rizk, A, Singh, N. V. 2018. (Dis)connectivities in wartime: The therapeutic geographies of Iraqi healthcare-seeking in Lebanon. Global Public Health 13(3): 288-297.

Dlaske, K. 2016. Shaping subjects of globalisation: at the intersection of voluntourism and the new economy. Multilingua 35(4): 415-440.

Duchêne, A. 2009. Marketing, management, and performance: Multilingualism as commodity in a tourism call centre. Language Policy, 8, 27-50.

Duchêne, A. 2011. Néolibéralisme, inégalités sociales et plurilinguismes: l'exploitation des ressources langagières et des locuteurs. Langage et Société, 136: 81-106.

Duchêne, Alexandre \& Monica Heller 2012. Language policy and the workplace. In Spolsky, B. (Ed.), The Cambridge Handbook of Language Policy (323-335). Cambridge: Cambridge University Press.

Fort, M., Mercer, M.A. and Gish, O. (eds.) 2004. Sickness and Wealth: The Corporate Assault on Global Health, Boston: South End Press.

Foucault, M. 1997. Technologies of the Self. In Rbinow, P. (Ed.), Ethics: Subjectivity and Truth (223319). New York: The New Press.

Gershon, I. 2011. Neoliberal Agency. Current Anthropology 52 (4): 537-555.

Gola, S. 2016. Medical tourism in India - in whose interest? Journal of International Trade Law and Policy 15 (2/3): 115-133.

Harvey, D. 2005. A brief history of neoliberalism. Oxford: Oxford University Press.

Hazarika, I. 2010. Medical tourism: its potential impact on the health workforce and health systems in India, Health Policy and Planning 25, 248-251.

Heller, M. 2010. Language as resource in the globalized economy. In N. Coupland (Ed.), The handbook of language and globalization, 349-365. Oxford: Wiley-Blackwell.

Heller, M. and A. Duchêne 2016. Treating language as an economic resource: Discourse, data, debates. In Nicolas Coupland (Ed.) Sociolinguistics: Theoretical Debates, 139-156. Cambridge: Cambridge University Press.

Kaspar, H. \& S. Reddy. 2017. Spaces of connectivity: The formation of medical travel destinations in Delhi National Capital Region (India). Asia Pacific Viewpoint 58, 2: 228-241.

Katz, M. L. 2001. Engineering a Hotel Family: Language Ideology, Discourse, and Workplace Culture. Linguistics and Education 12 (3): 309-343.

Kruk, M. E., Gage, A. D., Joseph, N. T., Danaei, G., García-Saisó, S., \& Salomon, J. A. 2018. Mortality due to low-quality health systems in the universal health coverage era: a systematic analysis of amenable deaths in 137 countries, The Lancet (online first): 1-10. DOI10.1016/S0140-6736(18)31668-4

Lorente, B. P. 2017. Scripts of Servitude: Language, Labor Migration and Transnational Domestic Work. Bristol: Multilingual Matters.

Muth, S. 2017. Russian as a commodity: medical tourism and the healthcare industry in post-Soviet Lithuania. International Journal of Bilingual Education and Bilingualism 20, 4: 404-416. 
Muth, S. 2018. 'The ideal Russian speaker is no Russian': Language commodification and its limits in medical tourism to Switzerland. Language Policy 17 (2): 217-237.

Muth, S. \& A. Del Percio. 2018. Policing for commodification: turning communicative resources into commodities (special issue). Language Policy 17 (2)

Ormond, M. 2013. Neoliberal governance and international medical travel in Malaysia. London: Routledge.

Österle, A., P. Balázs \& J. Delgado. 2009. Travelling for teeth: characteristics and perspectives of dental care tourism in Hungary. British Dental Journal 206 (8): 425-428.

Park, J. S. 2011. The promise of English: Linguistic capital and the neoliberal worker in the South Korean jobmarket. International Journal of Bilingual Education and Bilingualism 14 (4): 443-455.

Park, J. S. 2016. Language as pure potential. Journal of Multilingual and Multicultural Development 37 (5): 453 466.

Park, J. \& Wee, L. 2012. Markets of English: Linguistic capital and language policy in a globalizing world. London: Routledge.

Piller, I. \& J. Cho. 2013. Neoliberalism as language policy. Language in Society 42 (1): 23-44.

Piller, I. \& L. Lising. 2014. Language, employment, and settlement: Temporary meat workers in Australia. Multilingua, 33, 1-2: 35-59.

Piller, I. \& K. Takahashi. 2013. Language work aboard the low-cost airline. In A. Duchêne, M. Moyer \& C. Roberts (eds.) Language, migration and social inequalities: A critical sociolinguistic perspective on institutions and work, 95-117. Clevedon: Multilingual Matters.

Rahman, T. 2009. Language Ideology, Identity and the Commodification of Language in the Call Centers of Pakistan. Language in Society 38, 2, 233-258

Sharma, A. 2013. Medical tourism: emerging challenges and future prospects, Indian Journal of Business and Management Invention 2, 1, 21-29.

Shetty, P. 2010. Medical tourism booms in India, but at what cost? The Lancet 376, 671-672.

Smith, K. 2012. The problematization of medical tourism: a critique of neoliberalism. Developing World Bioethics. 12, 1: 1-8.

Smith, M., \& L. Puczkó, (Eds). 2014. Health, Tourism and Hospitality: Spas, Wellness and Medical Travel. London: Routledge.

Stan, S. 2015. Transnational health care practices of Romanian migrants in Ireland: inequalities of access and the privatisation of health care services in Europe. Social Science and Medicine, 124, 346-355.

Suryanarayan, N. 2017. The role of the Russian language in India's healthcare sector. Russian Journal of Linguistics 21 (3): 515-529.

Tan, P. K.W. \& R. Rubdy (2008). (Eds.), Language as Commodity: Global Structures, Local Marketplaces. London: Continuum.

Urciuoli, B. 2008. Skills and selves in the new workplace. American Ethnologist 35(2): 211-228.

Wee, L. 2015. The Language of Organizational Styling. Cambridge: Cambridge University Press. 
